\title{
Implementation of Intelligent Controller based Current Control Strategy for SRM Drive
}

\author{
U. Saptha Aswini Devi ${ }^{1}$, K. Ramesh Babu ${ }^{2}$ and Dr. P. Ramesh ${ }^{3}$ \\ ${ }^{I} M$-Tech Scholar Department of EEE, PACE Institute of Technology \& Sciences, \\ Ongole, A.P. \\ ${ }^{2}$ Associate Professor, Department of EEE, PACE Institute of Technology \& \\ Sciences, Ongole, A.P. India \\ ${ }^{3}$ Professor \& Head, Department of EEE, PACE Institute of Technology \& \\ Sciences, Ongole, A.P. \\ laswini.ummadi@gmail.com, ${ }^{2}$ ramesh.k@gmail.com, ${ }^{3}$ nannu.niky@gmail.com
}

\begin{abstract}
The design of the fuzzy logic controller is the control accomplishment as a feedback for significantly improving the dynamic performance of drive. The switches affecting in Switched reluctance motor (SRM) drive is receiving increasing attentions from various researchers as well as variable candidate for adjustable speed applications. Switched Reluctance Motors having simple structure and inherent mechanical strength without rotor winding. Torque-ripple reduction in switched reluctance motors (SRM) has become major research design. In servo control applications or when smooth control is entails at low speeds, reduction of torque ripple becomes the main concern in an adequate control strategy. In this intelligent controller such as Fuzzy Logic Controller (FLC) current compensating technique is employed for minimizing the torque ripples in SRM. For the purpose of comparison and the performance of conventional Proportional- Integral controller is also considered. With its flux linkage profile, SRM could be well modeled and simulated by using MAT Lab/Simulink.
\end{abstract}

Key words: SRM, PI controller, Flux profile

\section{Introduction}

The switched reluctance motor becomes an attractive alternative in variable speed drives, due to its advantages such as high reliability, structural simplicity, and low cost. Many researches discuss about SRM concerning design and control [2]. The important characteristic of the SRM is that the inductance of the magnetic circuit is a nonlinear function of the rotor position and phase current. So, for the control and optimization of this drive, the precise magnetic model is essential. Attaining this magnetic model is not an simple task, because the magnetic circuits operate at varying levels of saturation under the operating conditions [6]. In additional, the nonlinear characteristic of this plant represents challenge to the classical control. To overcome this drawback, some alternatives have been suggested in [4], using fuzzy systems.

The electronic approach is based on selecting an optimum combination of operating parameters, which include supply voltage, turn off and turn on angles, current level and shaft load [3]. Among these, a simple current modulation technique is extensively used for minimization of torque ripples in switched reluctance motor. The simple and accepted current compensating techniques can be implemented using both intelligent and conventional controllers. The conventional controllers requires to exact mathematical model of the systems are very sensitive to parameter variations. As switched reluctance motor presents strong non linear characteristics, the dynamic control of switched 
reluctance motor drive can be achieved by using intelligent controllers based on the artificial intelligent techniques such as FLC. However, in the case of the servo control applications or when smooth control is required for low speeds, the elimination of torque ripples becomes the main concern [4]. The application of a fuzzy logic based on adding a compensating current signal to switched reluctance motor is used to minimize the torque ripples is investigated. The dynamic response of the switched reluctance motor with proposed controllers PI and Fuzzy are examined.

\section{Mathematical Model for SRM}

The phase voltage equation of SRM can be given as:

$$
u=R i+\frac{d \Psi(\theta, i)}{d t}
$$

Where $\mathrm{u}$ is the phase voltage,

$\mathrm{R}$ is the winding resistance,

$\psi$ is the flux linkage,

$\theta$ is the rotor position and

I is the phase current.

Equation (1) can be expressed in discrete-time domain as:

$$
u(k)=R \cdot i(k)+\frac{\Psi(\theta(k+1), i(k+1))-\Psi(\theta(k), i(k))}{T}
$$

Where $\mathrm{T}$ is the control period and $\mathrm{k}$ is a positive integer representing the sampling instant.

The flux linkage profile $\psi(\theta(\mathrm{k}), \mathrm{i}(\mathrm{k}))$.

Using the information on flux linkage, conventional controller could be realized by

$$
u(k)=R \cdot i(k)+\frac{\Psi(\theta(k+1), i r e f)-\Psi(\theta(k), i(k))}{T}
$$

Where $i_{\text {ref }}$ is the reference current.

$\theta(\mathrm{k}+1)=\theta(\mathrm{k})+\omega \cdot \mathrm{T}$ and $\omega$ is the angular speed.

When (3) is substituted in (2), the response of system could be obtained as

$$
\Psi(\Theta(\mathrm{k}+1), \mathrm{i}(\mathrm{K}+1))=\Psi\left(\Theta(\mathrm{k}+1), \mathrm{i}_{\mathrm{ref}}\right)
$$

The transfer function of (4) is given as

$$
\frac{\Psi}{\Psi \text { ref }}=1
$$

Where $\psi_{\text {ref }}$ is the reference flux calculated by rotor position $\theta$ and reference current $i_{\text {ref. }}$.

It is shown that with the information of the accurate model of SRM, the controller could track the reference within one control period. Equation (5) also indicates the system with controller is inherently stable.

The gain observer could be designed as

$$
\begin{aligned}
& \beta(k+1)=\beta(k)+\Delta \beta(k) \\
& \Delta \beta(k)=\left\{\begin{array}{l}
\left|K_{1}\right|, e_{1} \cdot e_{2}>0 \text { and }\left|e_{1}\right|>B \\
0,\left|e_{1}\right| \leq B \\
-\left|K_{2}\right|, e_{1} \cdot e_{2}<0 \text { and }\left|e_{1}\right|>B
\end{array}\right.
\end{aligned}
$$

Where $\mathrm{K}_{1}$ and $\mathrm{K}_{2}$ are the gains of the gain observer.

The error transfer function of the system is

$$
e(k+1)=(1-\alpha \beta(k)) \Delta \Psi_{r e f}(k)+O(k)+(1-\alpha \beta(k)) e(k)
$$

Where

$$
\Delta \Psi_{\text {ref }}(k)=\Psi_{m}\left(\theta(k+1), i_{\text {ref }}\right)-\Psi_{m}\left(\theta(k), i_{\text {ref }}\right)
$$




$$
O(k)=\frac{(1-Y)}{Y} \alpha \cdot R_{m} \cdot i(k) \cdot T
$$

\section{Current Sample for Digital Control}

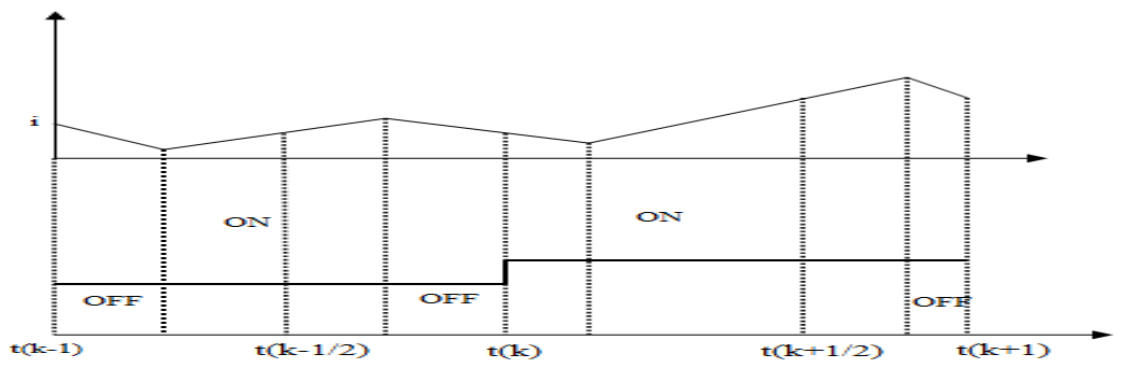

Figure 1. PWM Modulation

Figure 1 shows the PWM modulation for digital control. In the kth control period, current should be sampled at $\mathrm{t}(\mathrm{k})$.Proposes a predictive current controller increases the calculation burden and especially for nonlinear systems such as SRMs. Figure 3 shows that there is no switch action at $\mathrm{t}(\mathrm{k}-1 / 2)$, so the EMI noise is avoided. Furthermore, this method allows processing the duty ratio calculation in half period and will not bring delay to the control loop.

The estimation of sampling current is accurate if the current of each control period stays the same, as the $(\mathrm{k}-1)^{\text {th }}$ period, If current between each control period is changing, as the $\mathrm{k}^{\text {th }}$ period at that current is not accurate. If the current is not sampled accurately, it will bring oscillations to the control results and will reduce the performance of the controller.

\section{Fuzzy Logic Control}

Fuzzy logic control is constructed by a group of rules based on the human knowledge of system behavior and design of fuzzy logic controller can provide to desire both small signal and large signal dynamic performance at same time, fuzzy logic controller has been potential ability to improve the robustness of machine. 2.

The proposed block diagram of a fuzzy logic controller for SRM is as shown in Figure

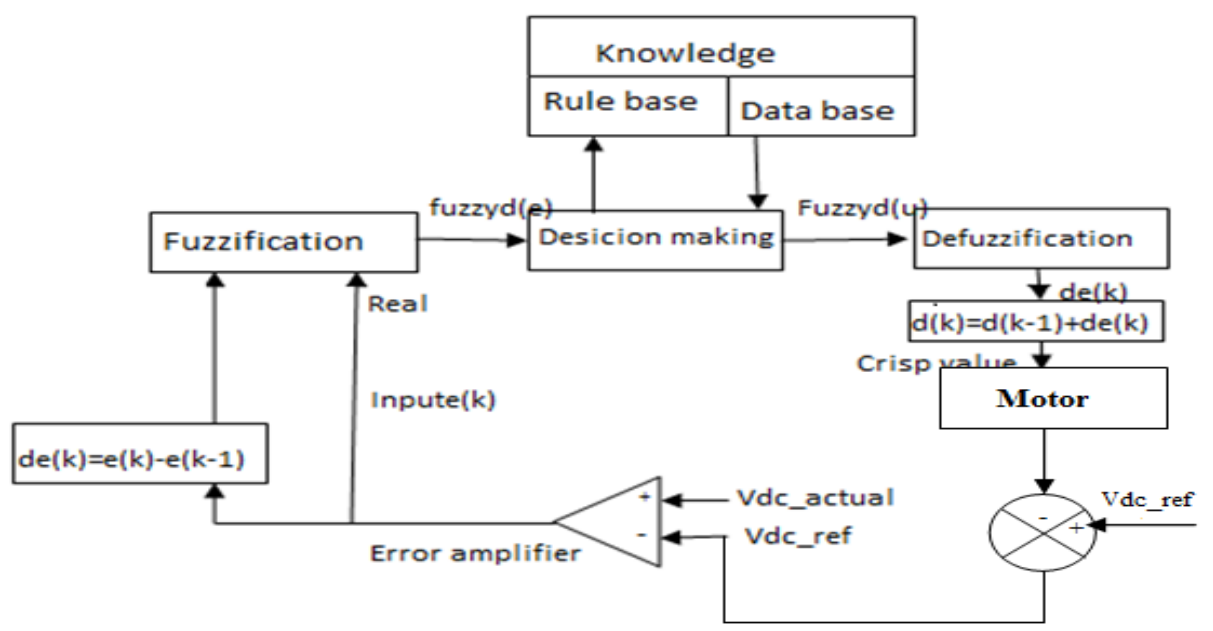

Figure 2. Block Diagram of the Fuzzy Logic Controller (FLC) for SRM 


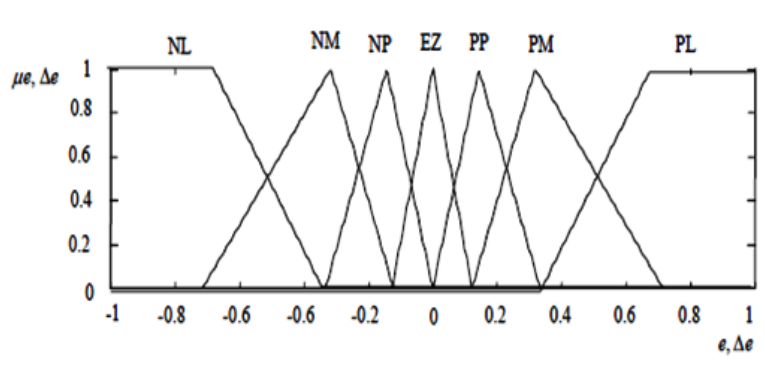

Figure 3. Membership Functions for Input, Change in Input, Output

The elements of this rule base table are determined based on the theory in the transient state, large errors need coarse control, which requires coarse in-put/output variables in the steady state; small errors need fine control, which requires fine input or output variables. Based on this the elements of rule table are obtained as shown in Table 1.

\section{Table 1. Rules for Error and Change of Error}

\begin{tabular}{|c|c|c|c|c|c|c|c|}
\hline$e$ & NL & NM & NS & EZ & PS & PM & PL \\
\hline NL & NL & NL & NL & NL & NM & NS & EZ \\
\hline NM & NL & NL & NL & NM & NS & EZ & PS \\
\hline NS & NL & NL & NM & NS & EZ & PS & PM \\
\hline EZ & NL & NM & NS & EZ & PS & PM & PL \\
\hline PS & NM & NS & EZ & PS & PM & PL & PL \\
\hline PM & NS & EZ & PS & PM & PL & PL & PL \\
\hline PL & NL & NM & NS & EZ & PS & PM & PL \\
\hline
\end{tabular}

\section{Results and Discussions}

Figure $4 \& 5$ shows the response of voltage, current, torque speed with PI and FLC controller. The performance of SRM is excellent using FLC controller as compared with conventional controller. The ripple content in the response of current, torque and speed is reduced with the use of fuzzy logic controller is better than conventional controller.

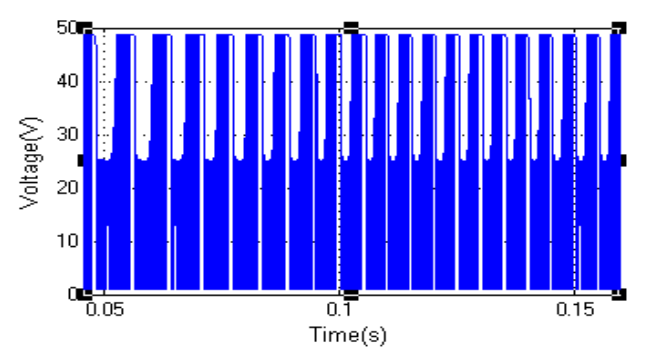

(a)
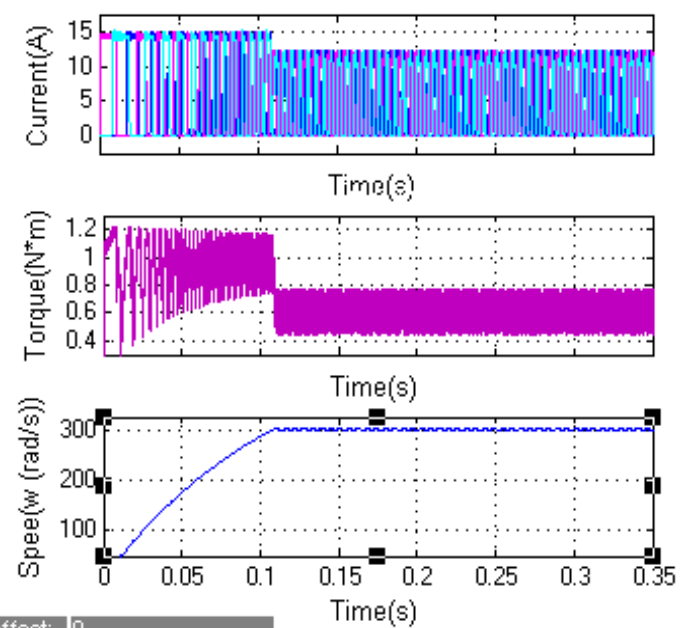

(b)

Figure 4. a) Voltage Response Using PI Controller b) Response of Current, Torque, Speed with PI Controller 

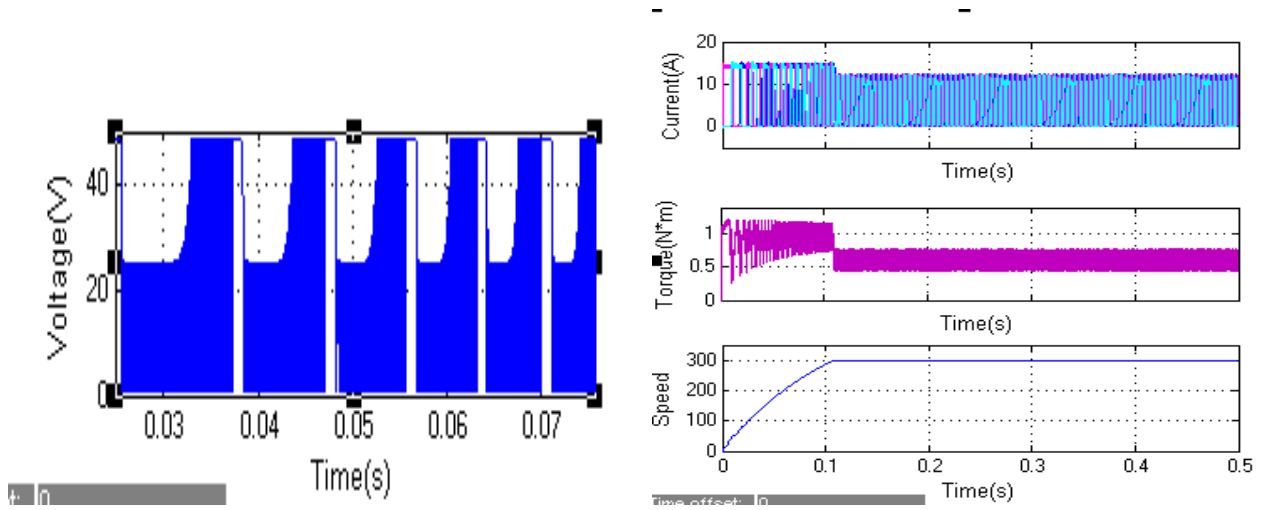

Figure 5. (a) Voltage Response Using Fuzzy Controller (b) Response of Current, Torque, Speed with Fuzzy Logic Controller

\section{Conclusion}

Fuzzy logic controller has been proposed in this work which reduces the ripple content and controls the current in the SRM. With the use of the current in the SRM is compensated which increases the dynamic stability and performance of the SRM drive. This paper presents fuzzy controller for SRM drives. An established the Observer is to assurance both fast response and stability of the FLC controller. An improved sampling approach is projected to compose the current sampling precise even under changeable current conditions. The Simulation results show that the proposed approach increases the performance of the SRM.

\section{References}

[1] F. Peng and A. Emadi, "A Digital PWM Current Controller for switched reluctance motor drive", IEEE trans, (2014) August.

[2] J.-W. Ahn, S.-J. Park and D.-H. Lee, "Hybrid excitation of SRM for reduction of vibration and acoustic noise", IEEE Trans. Ind. Electron., vol. 51, no. 2, (2004) April, pp. 374-380.

[3] D.-H. Lee, Z.-G. Lee and J.-W. Ahn, "Instantaneous Torque Control of SRM with a Logical Torque Sharing Method", Power Electronics Specialists Conference, PESC. IEEE, Orlando, FL, (2007) June, pp. 1784-1789.

[4] H. Goto, A. Nishimiya, H.-J. Guo and O. Ichinokura, "Instantaneous torque control using flux-based commutation and phase-torque distribution technique for SR motor EV", COMPEL Int. J. Comput. Math. Electr. Electron. Eng., vol. 29, no. 1, (2010), pp. 173-186.

[5] J. Ye, B. Bilgin and A. Emadi, "Comparative evaluation of power converters for $6 / 4$ and 6/10 switched reluctance machines", in Proc. 2012 IEEE Transportation Electrification Conference and Expo (ITEC), Dearborn, MI, (2012) June, pp. 1-6.

[6] Y. A.-R. I. Mohamed and E. F. El-Saadany, "Robust High Bandwidth Discrete-Time Predictive Current Control with Predictive Internal Model-A Unified Approach for Voltage-Source PWM Converters", IEEE Trans. Power Electron. vol. 23, no. 1, (2008) January, pp. 126-136.

[7] B. Shao and A. Emadi, "A digital PWM control for switched reluctance motor drives", in Proc. IEEE Vehicle Power and Propulsion Conference, Lille, France, (2010) September.

[8] P. Ramesh, and Dr. P. Subbaiah, "Rotor Position of Switched Reluctance Motor Using Sensorless Method", Journal of Theoretical and Applied Information Technology, vol. 70, no. 2, (2014).

[9] P. Ramesh and Dr. P. Subbaiah, "High Speed Charging and Discharging Current Controller Circuit to Reduce Back EMF by NeuroFuzzy Logic", International Journal of Applied Engineering Research, vol. 9, no. 22, (2014).

[10] P. Ramesh and Dr. P. Subbaiah, "Integrated noise removing filter for switched reluctance motor (SRM)", International Journal of Computer Applications, vol. 65, no. 14, (2013). 


\section{Authors}

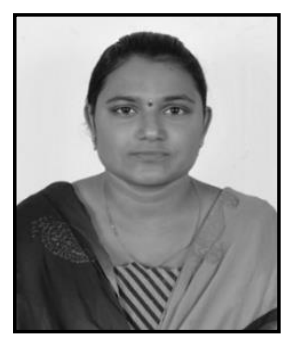

Ummadi Saptha Aswini Devi, received her B.Tech degree from Krishna Chaitanya Institute of Technology \&,Sciences Markapur, India in 2012.

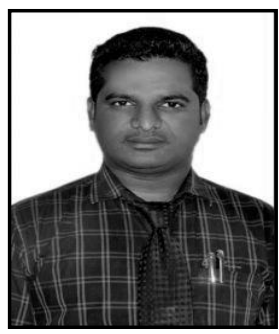

K. Ramesh Babu, Received the B.Tech. degree in Electrical and Electronics from Koneru Lakshmaiah College of Engineering, in 2004 and M. Teh. from JNTU, Kakinada in 2009. Currently he is working as Associate Professor in Electrical and Electronics Engineering in PACE Institute of Technology and Sciences, Ongole, Prakasam (dt), A.P, India. He is having 11 years of teaching experience. His interested areas are in the field of Power Converters, Electrical Drives and Renewable Energies.

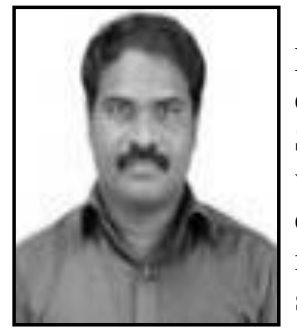

P. Ramesh, received B Tech, $\mathrm{M}$ tech degree and $\mathrm{PhD}$ in Electrical \& Electronics Engineering. Currently he is a professor and head of electrical \& electronics engineering Department at PACE Institute of Technology\& Sciences, Ongole, AP, India. He has published many technical papers in various international journals. He is a corporate member of the Institute of engineers, life member in Indian society of technical education and also member in association of international engineers, society of computer science and information technology. His area of research includes special machines, power and energy, soft computing and power electronics applications. 